\title{
Dual platelet antiaggregation therapy after myocardial revascularization surgery
}

\author{
(iD) Mateus Paiva Marques Feitosa ${ }^{1}$ \\ (iD) Carla David Soffiatti ${ }^{1}$ \\ Daime Paula Pessoa Linhares Filho 3 \\ (iD) Daniel Valente Batista \\ (iD) Heraldo Guedis Lobo Filho \\ (iD) Eduardo Gomes Lima ${ }^{3}$ \\ (iD) Carlos Vicente Serrano Júnior ${ }^{3}$
}

\begin{abstract}
1. Cardiology resident at the Heart Institute of the Hospital das Clínicas of the Faculty of Medicine of the University of São Paulo, São Paulo, Brasil 2. Department of Surgery of the Faculty of Medicine of the Federal University of Ceará, Ceará, Brasil 3. Department of Atherosclerosis of the Heart Institute of the Hospital das Clínicas of the Faculty of Medicine of the University of São Paulo, São Paulo, Brasil
\end{abstract}

\section{SUMMARY}

Coronary artery bypass graft (CABG) is a consolidated treatment in patients with coronary artery disease (CAD) for both symptom control and improvement of prognosis. The patency of venous grafts is still the most vulnerable point of the surgical treatment since it presents a high prevalence of occlusion both in the immediate postoperative period and in the long-term follow-up. Aspirin plays a well-established role in this setting, and for a long time, clopidogrel use has been restricted to patients allergic to aspirin. Recently, subgroup analyses of studies with different anti-platelet therapies have shown reduced mortality and cardiovascular events in patients on dual anti-platelet antiplatelet therapy (DAPT) undergoing CABG, although such studies have not been designed to evaluate this patient profile. However, there is still an insufficient number of randomized studies using DAPT in this context, resulting in a disagreement between the European and American cardiology societies guidelines regarding their indication and generating doubts in clinical practice.

KEYWORDS: Coronary artery bypass. Coronary artery disease. Aspirin. Platelet Aggregation Inhibitors.

Myocardial revascularization surgery (CABG) has been performed since the 1960s. It is routine treatment in patients with coronary artery disease (CAD) to control symptoms or improve prognosis. The evolution of perioperative care and surgical techniques increased the percentage of complete revascularization and reduced morbidity and mortality related to the procedure over the years.

The patency of venous grafts is still the vulnerable point of the surgical treatment with a prevalence of $10 \%-15 \%$ of occlusion in the immediate postoperative period and $50 \%$ occlusion in ten years. One of the primary mechanisms of occlusion in the first year is graft thrombosis. The use of aspirin, from the imme- diate postoperative period, in patients who undergo CABG, is already well established, with a reduction of mortality and combined adverse cardiac and cerebrovascular events, without a significant increase in bleeding. ${ }^{1-3}$

The progression of the atherosclerotic disease even after CABG is not unusual, culminating in adverse cardiac events. After all, the surgical procedure consists only of correcting the coronary lesions existent at the time of the procedure. Aspirin has a well-established role in this scenario, and for a long time, the use of clopidogrel was restricted to patients allergic to aspirin. However, the association of antiplatelet therapy has been shown to be beneficial in 
curbing the progression of atherothrombosis and to the viability of the venous grafts, in view of the possible additional effect of clopidogrel in reducing intimal hyperplasia, one of the main mechanisms of chronic coronary occlusion of venous grafts, an action which is not evidenced with the use of aspirin. ${ }^{4}$

Thus, given the possible benefits of inhibitors of P2Y12 receptors, the study TiCAB ${ }^{5}$, randomized and double-blind, assessed the use of aspirin compared with Ticagrelor, both in monotherapy in patients after surgical revascularization. After a one-year follow-up, the study, which was interrupted early due to lack of funding by the sponsor, did not show the superiority of the use of Ticagrelor in comparison to the use of aspirin for reducing cardiovascular outcomes and cerebrovascular diseases.

Since the monotherapy with the P2Y12 inhibitors did not show better results when compared with aspirin, it was suggested that Dual platelet antiaggregation therapy (Dapt) could be superior to the use of only one antiplatelet agent after CABG. In this sense, the eight-year follow-up of the Cascade ${ }^{6}$ study was published, comparing the effectiveness of Dapt with clopidogrel versus ASA and placebo. In this study, there was no difference between mortality or more significant cardiovascular events between the groups. Although there is less progression of atherosclerosis in the native beds, the patency of the grafts remained equal between the groups, as assessed using coronary angiography.

On the other hand, it is estimated that $30 \%$ of the population has some degree of resistance to clopidogrel. In acute coronary syndrome, for example, the effectiveness and safety of other antiplatelets, prasugrel or ticagrelor, are well established. Thus, several studies are being conducted to extend the indication of these platelets in relation to clopidogrel.

A subgroup analysis of the Plato ${ }^{7}$ study, which evaluated patients submitted to surgical revascularization, demonstrated a reduction of mortality and cardiovascular events in patients using dual antiplatelet dual with ticagrelor in comparison with Dapt with clopidogrel; however, the study was not designed to evaluate this profile of patients. Since the evidence remains scarce in the postoperative context, some randomized studies are being carried out to assess the real benefit of Dapt after CABG.

The Dacab trial ${ }^{8}$, an open and randomized study, evaluated the patency of venous grafts one year after CABG as a primary outcome in 500 patients into three branches (ASA, ticagrelor, and Dapt). A total of $12.2 \%$ was observed in patency favorable to the Dapt group (88.7\%) in relation to the ASA group (76.5\%), with no significant difference between the ASA and ticagrelor groups. The rate of events was low, with no difference in mortality and cardiovascular events in the three branches. There was also an increase of major bleedings between groups.

The POPular trial ${ }^{9}$, currently at the randomization stage and expected to wrap up this year (NCTO2352402), has as its objective to compare the patency of venous graft after a year between Dapt (ticagrelor and ASA) and monotherapy (ASA and placebo). The results of this study can contribute to a better understanding of the role of dual antiplatelet in surgical revascularization.

Although the majority of studies evaluate the patency of venous grafts as the primary outcome, there is still a difficulty in correlating the reduction of cardiovascular events and the patency of the grafts. The Prevent IV ${ }^{10}$ study demonstrated that the occlusion of venous grafts was not correlated with an increase of acute myocardial infarction in four years.

In summary, we found an insufficient quantity of randomized studies with the use of Dapt in patients undergoing CABG. New studies, preferably with clinical outcomes, therefore, are required to better consolidate specific recommendations after the procedure, since the lack of evidence results in an inconsistency between the recommendations of the American and European Societies of Cardiology. ${ }^{11,12}$

In stable patients, for example, the first considers the possibility of Dapt after surgical revascularization, while the second considers that the data are insufficient for such recommendation. In our practice, for stable patients submitted to CABG who did not make use of cardiopulmonary bypass and/or patients considered at low risk of bleeding, we consider the use of Dapt for 12 months.

For acute patients, to whom CABG is the revascularization therapy applied in a smaller proportion of cases (approximately 10\% of the patients in the Plato ${ }^{7}$ study), our position is favorable to the use of Dapt for at least 12 months. This recommendation is consolidated and referenced by the most recent European and American guidelines, both with class I recommendation.

Sources of Funding: none.

Conflict of interest: The authors declare there are no conflicts of interest. 


\section{RESUMO}

A cirurgia de revascularização miocárdica (CRM) é tratamento fundamental em pacientes com doença arterial coronariana (DAC) tanto para controle de sintomas quanto para melhora do prognóstico. A patência dos enxertos venosos ainda hoje é o ponto mais vulnerável do tratamento cirúrgico, por apresentar alta prevalência de oclusão tanto no pós-operatório imediato como no seguimento em longo prazo. A aspirina tem papel bem estabelecido neste cenário e, por muito tempo, o uso do clopidogrel ficou restrito a pacientes alérgicos a aspirina. Recentemente, análises de subgrupos de estudos com diferentes terapias antiplaquetárias demonstraram redução de mortalidade e eventos cardiovasculares em pacientes em uso de dupla antiagregação plaquetária (Dapt) submetidos à CRM, ainda que tais estudos não tenham sido desenhados para avaliar este perfil de pacientes. Contudo, há ainda uma quantidade insuficiente de estudos randomizados com uso de Dapt nesse contexto, resultando em uma discordância entre as diretrizes europeia e americana de cardiologia quanto à sua indicação e gerando dúvidas na prática clínica.

PALAVRAS-CHAVE: Ponte de artéria coronária. Doença da artéria coronariana. Aspirina. Inibidores da agregação de plaquetas.

\section{REFERENCES}

1. Motwani IG, Topol El. Aortocoronary saphenous vein graft disease: pathogenesis, predisposition, and prevention. Circulation. 1998;97(9):916-31.

2. Goldman S, Copeland I, Moritz T, Henderson W, Zadina K, Ovitt T, et al. Saphenous vein graft patency 1 year after coronary artery bypass surgery and effects of antiplatelet therapy. Results of a Veterans Administration Cooperative Study. Circulation. 1989;80(5):1190-7.

3. Mangano DT; Multicenter Study of Perioperative Ischemia Research Group. Aspirin and mortality from coronary bypass surgery. N Engl J Med. 2002;347(17):1309-17.

4. Herbert JM, Dol F, Bernat A, Falotico R, Lalé A, Savi P. The antiaggregating and antithrombotic activity of clopidogrel is potentiated by aspirin in several experimental models in the rabbit. Thromb Haemost. 1998;80(3):5128.

5. ClinicalTrials.gov [Internet]. Bethesda (MD): National Library of Medicine - Identificador NCT 01755520, Study comparing ticagrelor with aspirin for prevention of vascular events in patients undergoing CABG (TiCAB); 24 Dezembro 2012. Disponível em: https://clinicaltrials.gov/ct2/show/ NCT01755520.

6. Hage A, Voisine P, Erthal F, Larose É, Glineur D, Chow B, et al. Eight-year follow-up of the Clopidogrel After Surgery for Coronary Artery Disease (CASCADE) trial. J Thorac Cardiovasc Surg. 2018;155(1):212-22.

7. Wallentin L, Becker RC, Budaj A, Cannon CP, Emanuelsson H, Held C, et al; PLATO Investigators. Ticagrelor versus clopidogrel in patients with acute coronary syndromes, N Engl J Med. 2009;361(11):1045-57.

8. Zhao Q, Zhu Y, Xu Z, Cheng Z, Mei I, Chen X, Wang X. Effect of Ticagrelor Plus Aspirin, Ticagrelor Alone, or Aspirin Alone on Saphenous Vein Graft Patency 1 Year After Coronary Artery Bypass Grafting: A Randomized Clinical trial. JAMA. 2018; 319 (16): 1677-1686.

9. ClinicalTrials.gov [Internet]. Bethesda (MD): National Library of Medicine
- Identificador NCT02352402, The effect of ticagrelor on saphenous vein graft patency in patients undergoing coronary artery bypass grafting surgery (POPular CABG); 2 Fevereiro, 2015. Disponível em: https://clinicaltrials.gov/ct2/show/NCT02352402.

10. Alexander $\mathrm{H}$, Hafley $G$, Harrington RA, Peterson ED, Ferguson TB $\mid r$, Lorenz TJ; PREVENT IV Investigators. Efficacy and safety of edifoligide, an E2F transcription factor decoy, for prevention of vein graft failure following coronary artery bypass graft surgery: PREVENT IV: a randomized controlled trial. JAMA. 2005;294(19):2446-54.

11. Levine GN, Bates ER, Bittl|A, Brindis RG, Fihn SD, Fleisher LA, et al. 2016 ACC/AHA guideline focused update on duration of dual antiplatelet therapy in patients with coronary artery disease: a report of the American College of Cardiology/American Heart Association Task Force on Clinical Practice Guidelines. An Update of the 2011 ACC/AHA/SCAl guideline for percutaneous coronary intervention, 2011 ACCF/AHA guideline for coronary artery bypass graft surgery, 2012 ACC/AHA/ACP/AATS/PCNA/ SCAI/STS guideline for the diagnosis and management of patients with stable ischemic heart disease, 2013 ACC/AHA guideline for the management of ST-elevation myocardial infarction, 2014 AHA/ACC guideline for the management of patients with non-ST-elevation acute coronary syndromes, and 2014 ACC/AHA guideline on perioperative cardiovascular evaluation and management of patients undergoing noncardiac surgery. Circulation. 2016;134(10):e123-55.

12. Valgimigli $M$, Bueno $H$, Byrne RA, Collet IP, Costa F, leppsson A; ESC Scientific Document Group; ESC Committee for Practice Guidelines (CPG); ESC National Cardiac Societies. 2017 ESC focused update on dual antiplatelet therapy in coronary artery disease developed in collaboration with EACTS: The Task Force for dual antiplatelet therapy in coronary artery disease of the European Society of Cardiology (ESC) and of the European Association for Cardio-Thoracic Surgery (EACTS). Eur Heart I. 2018;39(3):213-60. 